Oikos 000: 001-008, 2010

doi: $10.1111 / j .1600-0706.2010 .17769 . x$

(C) 2010 The Authors. Journal compilation (C) 2010 Oikos

Subject Editor: Lonnie Aarssen. Accepted 5 February 2010

\title{
Evolution of dispersal traits along an invasion route in the wind-dispersed Senecio inaequidens (Asteraceae)
}

\author{
Arnaud Monty and Grégory Mahy \\ A. Monty (arnaud.monty@ulg.ac.be) and G. Mahy, Biodiversity and Landscape Unit, Gembloux Agrio-Bio Tech, Univ. of Liege, Passage des \\ Déportés, 2, BE-5030 Gembloux, Belgium.
}

\begin{abstract}
In introduced organisms, dispersal propensity is expected to increase during range expansion. This prediction is based on the assumption that phenotypic plasticity is low compared to genetic diversity, and an increase in dispersal can be counteracted by the Allee effect. Empirical evidence in support of these hypotheses is however lacking. The present study tested for evidence of differentiation in dispersal-related traits and the Allee effect in the wind-dispersed invasive Senecio inaequidens (Asteraceae). We collected capitula from individuals in ten field populations, along an invasion route including the original introduction site in southern France. In addition, we conducted a common garden experiment from field-collected seeds and obtained capitula from individuals representing the same ten field populations. We analysed phenotypic variation in dispersal traits between field and common garden environments as a function of the distance between populations and the introduction site. Our results revealed low levels of phenotypic differentiation among populations. However, significant clinal variation in dispersal traits was demonstrated in common garden plants representing the invasion route. In field populations, similar trends in dispersal-related traits and evidence of an Allee effect were not detected. In part, our results supported expectations of increased dispersal capacity with range expansion, and emphasized the contribution of phenotypic plasticity under natural conditions.
\end{abstract}

The range of an increasing number of plant species is expanding due to introductions, migration, and/or climate change (Pitelka 1997, Vitousek et al. 1997). The success of range expansion is strongly influenced by dispersal strategies. Therefore, an enhanced understanding of dispersal dynamics can improve invasion predictions (Travis and Dytham 2002). Seed dispersal is an integral component of plant life history, and fundamental in determining spatial patterns, population growth rates, and rates of species advance following climatic or other environmental change (Clobert et al. 2001, Levin et al. 2003). Several scenarios explain the evolution of dispersal strategies. In a competitive framework, a specific mode of dispersal may be favoured even if it is costly, provided that it results in establishment of the disperser over the nondisperser (Hamilton and May 1977). During range expansion, long-dispersed progeny has the opportunity to exploit habitats beyond the current range, and hence to be advantaged. This intrinsic advantage to dispersers is enhanced due to reduced competition among close relatives, especially sibs (Dieckmann et al. 1999). Furthermore, dispersal can reduce inbreeding and the potential for deleterious genetic effects (Moore and Ali 1984, Dieckmann et al. 1999).

In wind-dispersed Asteraceae, dispersal success is contingent on both propagule mass and dispersal structure (i.e. pappus) size (Matlack 1987), which are involved in separate, though related, ecological functions (Cappuccino et al. 2002). A large pappus and a light propagule are expected to favour dispersal, whereas a heavy propagule is expected to produce large and more vigorous seedlings (Black 1957, Dolan 1984), presumably conferring a competitive advantage (Roach and Wulff 1987). Tradeoffs between propagule mass and dispersal structure size might therefore be the result of contrasting forms of selection. Previous studies have analysed dispersal trait variation in plants, primarily in Asteraceae (McGinley 1989, Venable and Burquez 1990, Prince and Benoit 1995, Cody and Overton 1996, Welham and Setter 1998, O'Connell and Eckert 2001, Flann et al. 2002, Soons and Heil 2002, Gravuer et al. 2003, Riba et al. 2005). These studies reported evidence of variation in seed and pappus traits, and in some cases concluded the observed variation was the result of rapid evolutionary processes. However, the majority of these studies were performed from diaspores collected under natural conditions, and the variation may be the result of genetic and environmental effects. Generally, the contribution of phenotypic plasticity to seed dispersal traits is not well understood (Olivieri and Berger 1985, Donohue et al. 2005). Riba et al. (2005) used both diaspores from field populations and a common garden to address phenotypic variation in seed dispersal traits. This approach allowed for a separation of genetic-based differences and phenotypic plasticity in response to environmental variation.

In invasive plant species, variation in dispersal traits may be expected for range expansion (Holt 2003). During early 
naturalization, short-distance dispersal that extends population size incrementally should be favoured by selection because long-dispersed descendants are likely to suffer a strong Allee effect (Allee 1931, Lewis and Kareiva 1993, Stephens et al. 1999, Cappuccino 2004), i.e. a reduction in reproductive output due to low density and subsequent mate unavailability. During colonization, individuals exploiting new areas descend from good colonizers and thus are expected to have genes that confer high dispersal capacity. Moreover, they are the primary progenitors to the subsequent generations. Within newly founded populations, environmental conditions may in turn act on the selection for higher dispersal (Dytham 2009). The individuals and resulting populations at the invasion front will likely face selection for traits conferring effective dispersal and an increase in dispersal ability during invasion is expected (Travis and Dytham 2002, Holt 2003). At an invasion front, however, population densities may be low, and reproduction in small populations may be inhibited due to the Allee effect (Allee 1931, Taylor and Hastings 2005). Dispersal evolution during range expansion has been mainly approached through predictive modelling (Travis and Dytham 2002, Holt 2003, Phillips et al. 2008). Travis and Dytham's model (2002), which focus on alien species invasion from a single introduction source, indicates that the best dispersers are selected during invasion. Therefore, selection may result in a more rapid expansion than expected under evolutionary stasis. But when the Allee effect was considered in the model, results showed that invasion was slowed due to a decrease in diaspore survival outside the current range and in selection for dispersal. Clearly, this approach lacks the empirical validation required to fully understand the properties inherent in invasive plant species. To our knowledge, no empirical studies on seed dispersal trait variation along an invasion route have been published (but see Phillips et al. 2008 for an example in animal dispersal). This may be due to several constraints in methodology: 1) the relationship between dispersal and diaspore traits must be assessed, 2) the invasion history and ideally, the particular invasion route must be documented, and 3) diaspore traits should be analysed from field collections and those grown under controlled conditions (Riba et al. 2005).

In southern France, Senecio inaequidens (Asteraceae) is particularly well suited to serve as a model species to study the evolutionary history of invasive plants. The species has a well documented invasion history, including evidence of a single introduction site (Guillerm et al. 1990, Ernst 1998). In the present study, we analysed dispersal-related traits from 837 diaspores representing 99 S. inaequidens field and common garden individuals, to test the hypothesis that dispersal capacity increases with range expansion. We looked for an Allee effect among field populations, based on the number of achenes per flower head and the rate of achene abortion.

\section{Material and methods}

\section{Study organism}

Senecio inaequidens is a short-lived perennial native to South Africa and Lesotho, with a life span of 5-10 years (Ernst 1998, Brunel 2003, Lafuma et al. 2003). The species typically reaches $1 \mathrm{~m}$ in height, with numerous stems bearing yellow capitula. Individuals can produce up to 1500 flower heads during the flowering period, even in the first year following germination, and each capitulum bears approximately one hundred achenes (Lopez-Garcia and Maillet 2005). Germination can occur soon after dispersal, i.e. during the same season (Monty unpubl.). In France, flowering occurs from April through December. S. inaequidens is pollinated by many different generalist insects, including Hymenoptera, Lepidoptera and Diptera (Ernst 1998). Achenes are mainly wind-dispersed (Monty et al. 2008).

Senecio inaequidens was accidentally introduced to Europe in the late 19th - early 20th centuries where only tetraploids are reported. In its native range, the species occurs as two co-existing cytotypes (Lafuma et al. 2003). Several introductions occurred in Europe, each tied to wool importation (Lousley 1961, Ernst 1998). For several decades, specimens were only documented in the vicinity of European woolprocessing centres (Ernst 1998): Hannover (Germany) in 1889 and Bremen (Germany) in 1886; Edinburgh (UK) in 1928; Verona (Italy) in 1947 (Pignatti 1982); Liège (Belgium) in 1892 (Verloove 2006); and Mazamet (France) in 1936 (Guillerm et al. 1990). In southern France, Guillerm et al. (1990) documented a progressive colonization of the species, and found that for decades, it was only reported in the vicinity of the wool-processing centre of Mazamet. It was not until after 1950 that it steadily expanded throughout areas geographically outside the existing wool industrial centres. By the 1970s, the species had colonized areas of southwestern France well within the first introduction region and was considered an agricultural weed. In the early 1980s, the species reached the Mediterranean coast from Mazamet. Its expansion continued south from the mid- to late-1980s, and was subsequently reported from the Iberian Peninsula (Casasayas Fornell 1990). The species also colonized the Oriental Pyrenean, and was first recorded in Nohèdes (altitude ca $800 \mathrm{~m}$ ) in 1987 (Cottrel et al. 1998). This uphill colonization continued (Cottrel et al. 1998), and the species is presently distributed at elevations reaching $1700 \mathrm{~m}$, well within the Pyrenean. Figure 1 was adapted from Guillerm et al. (1990). Occurrence of the species referenced in the peer-reviewed literature were reported on the map with the year of occurrence (Aseginolaza et al. 1984, Guillerm et al. 1990, Cottrel et al. 1998, Garcia-Serrano et al. 2004) to illustrate the chronology of $S$. inaequidens range expansion in southern France, from the wool-processing centre of Mazamet. Not all existing populations are therefore reported on the map. Since the species is abundant in this region, the exact year of population establishment is generally unknown and we assumed the chronology inferred from published occurrence to be representative of the whole colonization in southern France. If the species is abundant in this area, to date, $S$. inaequidens remains absent from several areas in central and eastern France, indicating that invasion fronts from Mazamet and other introduction sites (Belgium, Italy) have not yet converged (Monty unpubl.). The invaded area represented in Fig. 1 is thus poorly connected to other invaded areas in Europe.

Due to a particularly well-documented invasion history, S. inaequidens has been used as a model species in several evolutionary studies (Lafuma and Maurice 2007, Bossdorf 


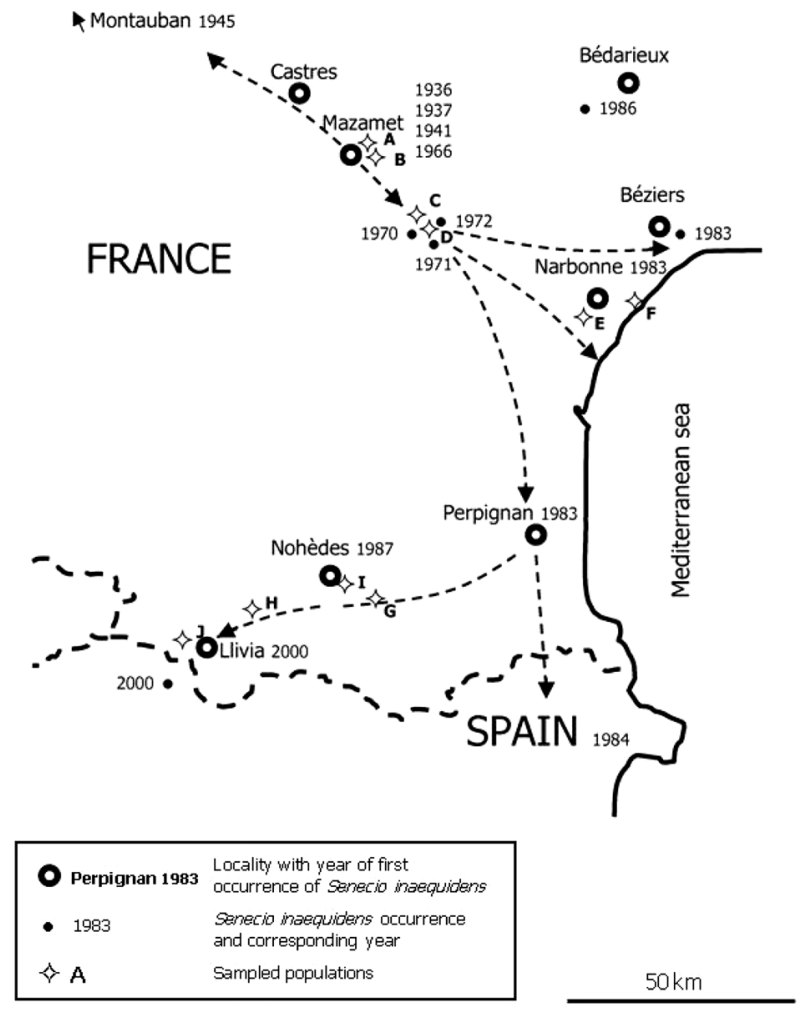

Figure 1. Progressive expansion chronology of Senecio inaequidens in southern France from the wool-processing centre of Mazamet, and sampled populations (A to J). Occurrences at the indicated localities are given where available from the peer-reviewed literature. Adapted from Guillerm et al. 1990.

et al. 2008, Monty et al. 2009, Monty and Mahy 2009). Most notably, a common garden study revealed that $S$. inaequidens experienced clinal genetic differentiation in growth traits during its invasion in southern France (Monty and Mahy 2009).

\section{Populations at increasing distances from the source}

Based on the $S$. inaequidens expansion chronology in southern France (Fig. 1), we selected ten populations at increasing distance from the initial introduction site of Mazamet (Guillerm et al. 1990). Populations were located along the invasion route (Fig. 1, see also Table 1 in Monty and Mahy 2009), first towards the Mediterranean, then along the Mediterranean coast, and into the Pyrenean towards northern Spain. The source population was located at an abandoned wool-processing factory in Mazamet, at the site where the species was first recorded. For each population, the expansion distance $(\mathrm{ED}, \mathrm{km})$ from the source was calculated as the shortest distance along a road using $<$ www.viamichelin.fr $>$. Road distance was more relevant than air distance because $S$. inaequidens is known to follow roads and railways during colonization (Ernst 1998). The altitude (ALT, $\mathrm{m}$ ) of each population was derived from topographic maps. In each population, the total number of individuals (NTOT) was counted. On 12 randomly selected individuals per population, the distances to the three nearest neighbours were measured, and the average of the 36 values was used as an estimate of the population density $(\mathrm{DNN}, \mathrm{cm})$.

\section{Sampling design}

We compared diaspores collected in the field and from a common garden experiment. In November 2005, we randomly collected achenes from ten individuals per population for a common garden experiment. The achenes were sown and thinned to one descendant per parent plant in a randomized block design on an open field in Gembloux, central Belgium (Monty and Mahy 2009). Free-pollinated capitula were collected from common garden plants in summer-early autumn 2006. We collected one capitulum per plant individual on three to six individuals per population. The total number of individuals sampled was 45. In November 2007, we randomly selected five to six individuals per field population (the individuals were assumed to be different from those sampled in 2005), and collected one capitulum per plant. The total number of individuals sampled was 54. All capitula were stored together at room temperature in pierced boxes until the diaspores were measured in September 2008. The number of nondeveloped (aborted) diaspores (NAD) and the total number of diaspores (ND) were determined for each capitulum. Non-developed diaspores are typically flat and whitish, and easy to distinguish from viable ones.

\section{Diaspore traits}

Dispersal capability of wind-dispersed diaspores can be successfully predicted from diaspore terminal velocity, which can be accurately estimated from morphological characteristics (Sheldon and Burrows 1973, Platt and Weiss 1977, Morse and Schmitt 1985, Augspurger and Franson 1987, Matlack 1987, Cody and Overton 1996, Gravuer et al. 2003). A recent study indicated that terminal velocity and dispersal of $S$. inaequidens diaspores could be predicted using a single trait parameter: the square root of the plume loading (Monty et al. 2008). Plume loading is defined as the ratio of the diaspore mass to the area of the horizontal projection of the pappus (Augspurger and Franson 1987, Matlack 1987). The lighter the diaspore and the larger the pappus, the lower the plume loading. Low plume loading induces low terminal velocity and therefore, increases dispersal distance.

Seven to 10 diaspores per capitulum were measured with a total sample size of $\mathrm{n}=375$ from the common garden and $n=462$ from field populations. An important withincapitulum variation has indeed been reported in the study species (Monty et al. 2008). For each diaspore, we measured pappus diameter $(\mathrm{PD}, \mathrm{mm})$ to the nearest $0.01 \mathrm{~mm}$ using an electronic digital calliper. After removing the pappus, the diaspores were weighed to the nearest $0.001 \mathrm{mg}$. Plume loading (or mass-area ratio, MAR, $\mathrm{kg} \mathrm{m}^{-2}$ ) was calculated as

$$
\mathrm{MAR}=\frac{4 \times \mathrm{AM}}{\pi \times \mathrm{PD}^{2}}
$$

where $\mathrm{AM}$ is the achene mass (mg).

\section{Data analysis}

We analysed the variation in ND and in the ratio NAD/ND, i.e. the proportion of aborted achenes, among field populations. Variation in these two capitulum traits along the 
Table 1. Backward-selected linear mixed effect models for the effect of the growing environment (GE), the expansion distance (ED) and the altitude (ALT) on dispersal traits (plume loading MAR and its two components, achene mass AM and pappus diameter PD) of S. inaequidens, along the invasion route in southern France. The dataset included 837 samples from 99 individuals, in 10 populations. As the GEXED interaction was significant, a model was fitted for each GE, separately. Significant results are in bold.

\begin{tabular}{|c|c|c|c|c|c|c|c|c|c|}
\hline \multirow{2}{*}{$\begin{array}{l}\text { Variables } \\
\text { All data }\end{array}$} & \multicolumn{3}{|c|}{ MAR } & \multicolumn{3}{|c|}{$\mathrm{AM}$} & \multicolumn{3}{|c|}{ PD } \\
\hline & F-value & p-value & DF & F-value & $\mathrm{p}$-value & DF & F-value & p-value & DF \\
\hline Intercept & 38269.80 & $<0.0001$ & 1,738 & 22813.19 & $<0.0001$ & 1,738 & 6445.22 & $<0.0001$ & 1,738 \\
\hline GE & 0.22 & 0.640 & 1,87 & 0.56 & 0.458 & 1,87 & 0.02 & 0.889 & 1,87 \\
\hline ED & 0.66 & 0.441 & 1,8 & 0.00 & 0.974 & 1,8 & 1.22 & 0.302 & 1,8 \\
\hline GE×ED & 13.25 & 0.0005 & 1,87 & 6.25 & 0.014 & 1,87 & 4.98 & 0.028 & 1,87 \\
\hline \multicolumn{10}{|c|}{ Common garden } \\
\hline Intercept & 21830.70 & $<0.0001$ & 1,330 & 1597.58 & $<0.0001$ & 1,330 & 5053.32 & $<\mathbf{0 . 0 0 0 1}$ & 1,330 \\
\hline $\mathrm{ED}$ & 10.89 & 0.011 & 1,8 & 2.63 & 0.143 & 1,8 & 8.60 & 0.019 & 1,8 \\
\hline \multicolumn{10}{|c|}{ Field populations } \\
\hline Intercept & 19692.68 & $<0.0001$ & 1,408 & 1889.51 & $<0.0001$ & 1,408 & 3049.45 & $<\mathbf{0 . 0 0 0 1}$ & 1,408 \\
\hline ALT & 3.72 & 0.090 & 1,8 & 4.44 & 0.068 & 1,8 & 0.385 & 0.552 & 1,8 \\
\hline
\end{tabular}

transect can reveal fitness variation among field population, notably due to an Allee effect. A linear mixed-effects model was fitted with ND as response, NTOT, DNN, ED and ALT as predictors and population as grouping factor (Bates 2005). A similar model was fitted with NAD/ND as response. An Allee effect would typically be illustrated by a relationship between the proportion of non-developed achenes and the population density or size, and one could expect those demographic parameters to decrease with increasing geographic distance or altitude. Pearson's correlations were calculated between the predictors.

Variation in dispersal capacity of individuals was analysed using linear mixed-effects models with MAR as response. The growing environment GE (common garden vs field populations), the expansion distance ED, and the altitude ALT, as well as the interactions between GE and ED and between the GE and ALT, were included as fixed predictors. Population and individuals (nested within population) were included as grouping, i.e. random, factors (Bates 2005). ED was included to test our main hypothesis that dispersal capacity evolved along the invasion route. The interaction thereof with GE was included to assess the genetic origin of the influence of ED. ALT, as well as the interaction thereof with GE, was included as altitude can have a confounding effect with expansion distance along the study transect. A similar model was then fitted with AM and PD as responses, to analyze the effects of the different predictors on the two components of MAR. We used backward selection to remove non-significant terms from the initial model. In the case of a significant effect of the interaction between GE and other predictors, we fitted a linear mixed-effects model for each growing environment, separately. Statistical analysis was executed using $\mathrm{R}$ ver. 2.0.8 (R Development Core Team 2008). MAR data were $\log$-transformed to improve normality of residuals.

\section{Results}

\section{Demographic and fitness variation in field populations}

The study transect was $171 \mathrm{~km}$ long, and encompassed an altitudinal variation of $1633 \mathrm{~m}$. NTOT varied from 101 to 979 individuals along the transect. The source population was among the largest ones, with 912 individuals. DNN varied from $53.0 \mathrm{~cm}$ to $230.1 \mathrm{~cm}$. We found no significant effect of NTOT $\left(\mathrm{F}_{1,5}=3.342, \mathrm{p}=0.127\right)$, DNN $\left(\mathrm{F}_{1,5}=0.277, \mathrm{p}=0.621\right), \mathrm{ED}\left(\mathrm{F}_{1,5}=0.063, \mathrm{p}=0.812\right)$ or ALT $\left(\mathrm{F}_{1,5}=5.343, \mathrm{p}=0.068\right)$ on ND. Similarly, no significant effect of NTOT $\left(\mathrm{F}_{1,5}=0.345, \mathrm{p}=0.583\right)$, DNN $\left(\mathrm{F}_{1,5}=0.765, \mathrm{p}=0.421\right), \mathrm{ED}\left(\mathrm{F}_{1,5}=0.117, \mathrm{p}=0.746\right)$ or ALT $\left(\mathrm{F}_{1,5}=2.826, \mathrm{p}=0.154\right)$ was detected on the proportion of aborted achenes NAD/ND. Save for ALT and ED $(\mathrm{r}=0.698, \mathrm{p}=0.025)$, predictors were not significantly correlated (NTOT and ED: $r=-0.522$; NTOT and ALT: $\mathrm{r}=-0.315$; NTOT and DNN: $\mathrm{r}=-0.453$; DNN and ED: $\mathrm{r}=0.092$; DNN and ALT: $\mathrm{r}=-0.021$; all $\mathrm{p}>0.1$ ), indicating that demographic parameters did not vary linearly along the transect.

\section{Diaspore trait variation}

As shown in Table 1, the influence of ED on MAR and its components (AM and PD) differed with GE, as reveal by the significant $\mathrm{GE} \times \mathrm{ED}$ interactions. In the common garden, MAR decreased $\left(\mathrm{F}_{1,8}=10.89, \mathrm{p}=0.011\right)$ and PD increased $\left(\mathrm{F}_{1,8}=8.60, \mathrm{p}=0.019\right)$ with increasing distance from the source population, whereas this was not the case in field populations. In the field, the influence of ALT on MAR $\left(\mathrm{F}_{1,8}=3.72, \mathrm{p}=0.090\right)$ and $\mathrm{AM}\left(\mathrm{F}_{1,8}=4.44, \mathrm{p}=0.068\right)$ was marginally significant.

\section{Discussion}

\section{Lack of evidence for an Allee effect}

No clear pattern of variation was found along the transect for the proxies of fitness we used. The proportion of aborted achenes mainly refers to the efficiency of crossings between individuals, whereas the total number of achenes per capitulum is assumed to express the fitness of individuals. It has to be noted, however, that the fitness of individuals also depends on the number of flower heads produced, the success of descendants, etc. We found no evidence for an Allee effect sensu stricto, i.e. no reduction in reproductive performance in relation to demographic parameters like population size 
or average distance between neighbouring plants. This result is congruent with those of Van Kleunen and Jonhson (2005) who found no evidence for an Allee effect in invasive populations of a nonclonal, insect-pollinated shrub, but contrast with those of Cappucino (2004). That fitness traits do not decline at the expanding front also suggests the species (at least for the populations we sampled) is expanding into good quality habitat, with sufficient pollinators, and/or that expansion has likely not yet reached equilibrium. Besides, demographic parameters appeared not to be correlated to expansion distance or altitude along the study transect, indicating they are most likely related to other environmental conditions. Travis and Dytham (2002) suggested that in the absence of an Allee effect, high rates of dispersal should be favoured by selection during invasions.

\section{Clinal trend under common garden conditions}

Previous analyses of intra-specific variation in dispersal traits have revealed increased dispersal potential in putatively more recently established plant populations (Olivieri et al. 1983, Peroni 1994). However, few studies of large-scale geographic variation in dispersal traits have been reported. Cwynar and MacDonald (1987) found increased dispersal potential in lodgepole pine populations at the migration front associated with post-glacial range expansion. Darling et al. (2008) found increased dispersal potential towards range margins in the endemic Abronia umbellate (Nyctaginaceae), which is consistent with enhanced selection for dispersal at range limits. In animals, the annual rate of progress of the cane toad Bufo marinus invasion front has increased since the toads first arrived, and individuals at the front have longer legs than toads in older (long-established) populations, enhancing their dispersal capacities (Phillips et al. 2006). These studies indicated that dispersal can be under different selection pressures in different parts of the range. Using a evolutionary simulation model, Dytham (2009) showed that habitat turnover, reduced reproductive success and reduced habitat quality all increase evolved dispersal distances at the margin, while increased cost of dispersal and reduced habitat density lead to lower evolved dispersal distances at the margins. Here we report a tenuous clinal variation in dispersal along an invasion route, in a spatial context, in relation to the distance to the site of first introduction of an invasive plant. If this distance coincides with a chronological pattern, it was preferred to population age fort the tested hypothesis was inherently spatial.

Monty et al. (2008) demonstrated that in S. inaequidens, plume loading (MAR) was integral in terminal velocity. It was therefore a suitable trait to assess dispersal capacity of diaspores or plant individuals. Even though rare long-distance dispersal are not only determined by terminal velocity (Nathan 2006, Nathan et al. 2008), terminal velocity was indeed repeatedly recognized as a key biotic determinants of dispersal (Gravuer et al. 2003, Nathan and Katul 2005, Monty et al. 2008). In the present study, we found a low level of differentiation in MAR among populations. However, this trait showed clinal variation in the common garden. Under controlled environmental conditions, plants originating from populations located further from the primary introduction site produced diaspores with a larger pappus, resulting in lower MAR and a higher dispersal potential. Because it was observed in a common garden, this variation among populations was, at least partially, under genetic control (Clausen et al. 1940). The predictive model of Travis and Dytham (2002) is congruent to these results. MAR reduction is primarily the result of an increase in pappus size, and not to variation in achene mass. It is important to note that pappus dimensions are essentially associated with dispersal ability, whereas achene mass is likely related to seedling fitness (Black 1957, Dolan 1984). Former studies that addressed the relationship between dispersal capacity and seedling fitness found a tradeoff between these two fitness traits, i.e. increased achene mass confers higher growth rates, but carries a cost in terms of dispersal ability (Meyer and Carlson 2001, Cappuccino et al. 2002, Píco et al. 2003).

In a recent study, we demonstrated that $S$. inaequidens exhibited clinal differentiation in growth traits during invasion in southern France (Monty and Mahy 2009). Specifically, plant height at initial flowering and maximum height decreased in mountainous populations as elevation and distance from Mazamet increased. In terms of dispersal, this phenotypic trend elicits a negative influence on the effective seed rain through a reduction in mean release height (Monty et al. 2008). Independent of environmental conditions, an antagonistic relationship between the following attributes may operate: a reduction in mean release height; and an increase in dispersal potential with an elevation gain and distance from the source population.

According to several studies, selection may act to reduce dispersal in heterogeneous environments where progeny survival is greater in the maternal environment than in the non-predictable dispersed environment (Mathias et al. 2001, Cheptou et al. 2008). In the future, assessing habitat heterogeneity within the invaded area of $S$. inaequidens in southern France could help better understanding the selection pressures acting on dispersal.

\section{Comparison between field and controlled conditions}

It is noteworthy that no pattern similar to the clinal trend in the common garden was detected in the field populations. Populations at the migration front exhibited a high potential for dispersal, but the phenotypes were not characteristic of better dispersers. If dispersal is under genetic influence, it is also a plastic trait, under many environmental influences. While this is clearly recognized in the literature about animal dispersal (Merckx and Van Dyck 2006), plasticity of dispersal and its evolutionary implications was poorly investigated in plants (but see Clobert et al. 2001, Imbert and Ronce 2001). Using a modelling approach, Ronce et al. (2005) predicted that selection should favour plastic strategies allowing plants to increase their dispersal rate in older population, in the context of ecological succession. As our transect follows a chronological colonization, populations near the source are expected to be older than populations near the migration front. The former can therefore show different patterns of phenotypic plasticity than the latter, thus obscuring the genetic trend in the field.

Few published studies comparing the levels of phenotypic variation under natural versus controlled conditions for dispersal-related traits are available (but see Riba et al. 
2005). Venable and Burquez (1990) found little difference in phenotypic variation between natural and controlled conditions for several plant traits in Heterosperma pinnatum (Asteraceae). Riba et al. (2005) reported a similar pattern, with comparable phenotypic variation in both growing environments. Our results also suggested that the levels of phenotypic variation are similar under natural versus controlled conditions (see error bars in Fig. 2). A decrease in phenotypic variation might be expected under controlled conditions, due to suppression of the environmental sources of variation. However, some authors have argued that controlled conditions might increase differentiation among populations (Mitchell-Olds and Rutledge 1986). Phenotypic variation in the field may not reflect the evolutionary potential of a species because of environmental effects. Alternatively, phenotypic variation measured in common gardens might not be associated with the levels of genetic variation actually present in natural populations, because of genotype $\times$ environment interactions. The present study showed a pattern of variation presumably dictated by growing conditions. The phenotypic differences observed in the field and common garden populations are most likely attributable to phenotypic plasticity. The distance-to-the-source study transect also followed an altitudinal gradient. However, we found no significant (but marginally significant) effect of altitude on dispersal capacity, indicating a low influence of climatic conditions. Soil nutrient levels, inter-specific competition and disturbance regimes may be partly responsible for the differences observed between field and common garden data (Ronce et al. 2005). In a study of maternal effects in $S$. inaequidens, Monty et al. (2009) suggested that a plastic response to environmental conditions, at least in some populations, explained variation in achene mass.

Most studies on the evolution of dispersal infer dispersal ability from field collected diaspores (Cody and Overton 1996, Gravuer et al. 2003), and consider the observed patterns of variation as genetically-based. Riba et al. (2005) revealed comparable differentiation patterns among populations in both controlled and natural conditions, lending support to these previous phenotypic studies. In the present study, we found no clear pattern of variation in the field but a significant one under controlled conditions. These results indicated that the study of seed dispersal evolution under controlled and field conditions conveys complementary pieces of information, especially when field conditions are varied which can enhance phenotypic plasticity.

\section{Conclusion}

This study is among the first to generate empirical evidence of dispersal trait evolution during plant invasion. We focussed on a short spatial scale to ensure a well documented, gradual, colonization history. Our study transect represented the colonization progression of the invasive $S$. inaequidens in southern France. During its range expansion towards the high Pyrenean, the species appears to have experienced slight selection in favour of effective dispersal traits. Based on the inferred genetic trend, a more rapid invasion should result by selection for better dispersers. Phenotypic differentiation was however low, and we did not detect better dispersing phenotypes in the field. Our results are congruent with
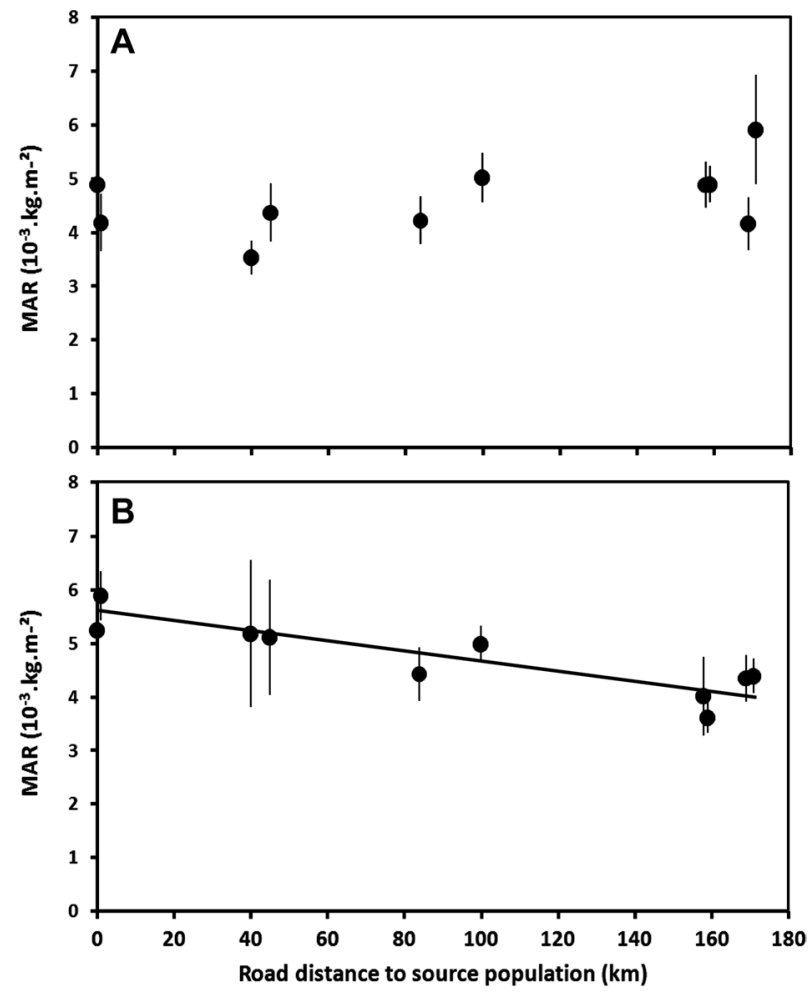

Figure 2. Population mean values of plume loading (MAR, $10^{-3} \mathrm{~kg}$ $\mathrm{m}^{-2}$ ) and standard errors, against road distance to the source population (expansion distance, $\mathrm{km}$ ), for each field and garden growing environment. (A) field populations; (B) common garden. The solid line represents the minimal backward-selected linear mixed effect model for common garden data.

recent models (Travis and Dytham 2002, Ronce et al. 2005) and highlight that the inclusion of phenotypic plasticity in modelling could improve dispersal predictions.

More attention should be paid to studies on dispersal evolution during plant invasion. In particular, the consequences of dispersal capabilities on the invasion pattern and on forecasting and monitoring invasive plant migration should be addressed, and at a broader geographic scale. However, current hypotheses still require further empirical validation. In order to elucidate the genetic patterns and trends of dispersal, studies should include an assessment of phenotypic variation under both controlled and field conditions.

Acknowledgements - We thank S. Maurice for useful information about French populations and Benjamin Cerisier for technical assistance during the research project. This research was supported by the project FRFC 2.4556.05 from the Belgian Fonds National de la Recherche Scientique (FNRS). Arnaud Monty has a postdoctoral position at the FNRS. The experiments in this study comply with the current laws of the country in which they were performed.

\section{References}

Allee, W. C. 1931. Animal aggregations. - Univ. of Chicaho Press. Aseginolaza, C. et al. 1984. Catálogos floristico de Álava, Vizcaya y Guipúzcoa. - Gobierno Vasco. 
Augspurger, C. K. and Franson, S. E. 1987. Wind dispersal of artificial fruits varying in mass, area, and morphology. Ecology 68: 27-42.

Bates, D. 2005. Fitting linear mixed models in R. - R News 5: 27-30.

Black, J. N. 1957. Seed size as a factor in the growth of subterranean clover (Trifolium subterraneum L.) under spaced and sward conditions. - Aust. J. Agric. Res. 8: 335-351.

Bossdorf, O. et al. 2008. Selection of preadapted populations allowed Senecio inaequidens to invade central Europe. - Div. Distr. 14: 676-685.

Brunel, S. 2003. Plantes envahissantes de la région méditerranéenne, Fiche No. 15. - Agence Méditerranéenne de l'Environnement.

Cappuccino, N. 2004. Allee effect in an invasive alien plant, pale swallow-wort Vincetoxicum rossicum (Asclepiadaceae). - Oikos 106: 3-8.

Cappuccino, N. et al. 2002. Spread of the invasive alien vine Vincetoxicumrossicum: tradeoffs between seed dispersability and seed quality. - Am. Midl. Nat. 148: 263-270.

Casasayas Fornell, T. 1990. Widespread adventive plants in Catalonia. - In: di Castri, F. et al. (eds), Biological invasions in Europe and the Mediterranean Basin. Kluwer Academic Publishers, pp. 61-84.

Cheptou, P. O. et al. 2008. Rapid evolution of seed dispersal in an urban environment in the weed Crepis sancta. - Proc. Natl Acad. Sci. USA 105: 3796-3799.

Clausen, J. et al. 1940. Experimental studies on the nature of species. I. Effect of varied environments on western North American plants. - Carnegie Inst. of Washington Publication.

Clobert, J. et al. (eds) 2001. Dispersal. - Oxford Univ. Press.

Cody, M. L. and Overton, J. M. 1996. Short-term evolution of reduced dispersal in island plant populations. - J. Ecol. 84: 5361.

Cottrel, V. et al. 1998. Mécanismes de l'invasion par Senecio inaequidens sur le territoire de Nohèdes (Pyrénées Orientales). - In: Maillet, J. (ed.), Proc. 6th Mediterranean Symp. E.W.R.S. ENSAM, pp. 41-42.

Cwynar, L. C. and MacDonald, G. M. 1987. Geographical variation of lodgepole pine in relation to population history. - Am. Nat. 129: 463-469.

Darling, E. et al. 2008. Increased seed dispersal potential towards geographic range limits in a Pacific coast dune plant. - New Phytol. 178: 424-435.

Dieckmann, U. et al. 1999. The evolutionary ecology of dispersal. - Trends. Ecol. Evol. 14: 88-90.

Dolan, R. W. 1984. The effect of seed size and maternal source on individual size in a population of Ludwigia leptocarpa (Onagraceae). - Am. J. Bot. 71: 1302-1307.

Donohue, K. et al. 2005. Genetic basis and consequences of niche construction: plasticity-induced genetic constraints on the evolution of seed dispersal in Arabidopsis thaliana. - Am. Nat. 165: 537-550.

Dytham, C. 2009. Evolved dispersal strategies at range margins. Proc. R. Soc. Lond. B. 276: 1407-1413.

Ernst, W. H. O. 1998. Invasion, dispersal and ecology of the South African neophyte Senecio inaequidens in the Netherlands: from wool alien to railway and road alien. - Acta Bot. Neerl. 47: 131-151.

Flann, C. et al. 2002. Morphological variation in Leptorhynchos squamatus (Gnaphalieae: Asteraceae). - Aust. Syst. Bot. 15: 205-219.

Garcia-Serrano, H. et al. 2004. Factors that limit the emergence and establishment of the related aliens Senecio inaequidens and Senecio pterophorus and the native Senecio malacitanus in Mediterranean climate. - Can. J. Bot. 82: 1346-1355.

Gravuer, K. et al. 2003. Dispersal biology of Liatris scariosa var. novae-angliae (Asteraceae), a rare New England grassland perennial. - Am. J. Bot. 90: 1159-1167.
Guillerm, J. L. et al. 1990. The invading weeds within the Mediterranean Basin. - In: di Castri, F. et al. (eds), Biological invasions in Europe and the Mediterranean Basin. Kluwer Academic Publishers, pp. 61-84.

Hamilton, W. D. and May, R. M. 1977. Dispersal in stable habitats. - Nature 269: 578-581.

Holt, R. D. 2003. On the evolutionary ecology of species' ranges. - Evol. Ecol. Res. 5: 159-178.

Imbert, E. and Ronce, O. 2001. Phenotypic plasticity for dispersal ability in the seed heteromorphic Crepis sancta (Asteraceae). Oikos 93: 126-134.

Lafuma, L. and Maurice, S. 2007. Increase in mate availability without loss of self-incompatibility in the invasive species Senecio inaequidens (Asteraceae). - Oikos 116: 201-208.

Lafuma, L. et al. 2003. Ploidy level and origin of the European invasive weed Senecio inaequidens (Asteraceae). - Plant Syst. Evol. 243: 59-72.

Levin, S. A. et al. 2003. The ecology and evolution of seed dispersal: a theoretical perspective. - Annu. Rev. Ecol. Evol. Syst. 34: 575-604.

Lewis, M. A. and Kareiva, P. M. 1993. Allee dynamics and the spread of invading organisms. - Theor. Popul. Biol. 43: 141-158.

Lopez-Garcia, M. C. and Maillet, J. 2005. Biological characteristics of an invasive African species. - Biol. Invas. 7: 181-194.

Lousley, J. E. 1961. A census list of wool aliens found in Britain, 1946-1960. - Proc. Bot. Soc. Brit. Isles 4: 221-247.

Mathias, A. et al. 2001. Divergent evolution of dispersal in a heterogeneous landscape. - Evolution 55: 246-259.

Matlack, G. R. 1987. Diaspore size, shape, and fall behavior in wind-dispersed plant species. - Am. J. Bot. 74: 1150-1160.

McGinley, M. A. 1989. Within and among plant variation in seed mass and pappus size in Tragopogon dubious. - Can. J. Bot. 67: $1298-1304$.

Merckx, T. and Van Dyck, H. 2006. Landscape structure and phenotypic plasticity in flight morphology in the butterfly Pararge aegeria. - Oikos 113: 226-232.

Meyer, S. E. and Carlson, S. L. 2001. Achene mass variation in Ericameria naussosus (Asteraceae) in relation to dispersal ability and seedling fitness. - Funct. Ecol. 15: 274-281.

Mitchell-Olds, T. and Rutledge, J. J. 1986. Quantitative genetics in natural plant populations: a review of the theory. - Am. Nat. 127: 379-402.

Monty, A. and Mahy, G. 2009. Clinal differentiation during invasion: Senecio inaequidens along altitudinal gradients in Europe. - Oecologia 159: 305-315.

Monty, A. et al. 2008. Seed rain pattern of the invasive weed Senecio inaequidens (Astreraceae). - Belg. J. Bot. 141: 51-63.

Monty, A. et al. 2009. An explicit test for the contribution of environmental maternal effects to rapid clinal differentiation in an invasive plant. - J. Evol. Biol. 22: 917-926.

Moore, J. and Ali, R. 1984. Are dispersal and inbreeding avoidance related? - Anim. Behav. 32: 94-112.

Morse, D. H. and Schmitt, J. 1985. Propagule size, dispersal ability, and seedling performance in Asclepias syriaca. - Oecologia 67: 372-379.

Nathan, R. 2006. Long-distance dispersal of plants. - Science 313: 786-788.

Nathan, R. and Katul, G. G. 2005. Foliage shedding in deciduous forests lifts up long-distance seed dispersal by wind. - Proc. Natl Acad. Sci. USA 102: 8251-5256.

Nathan, R. et al. 2008. Mechanisms of long-distance seed dispersal. - Trends. Ecol. Evol. 23: 638-647.

O'Connell, L. M. and Eckert, C. G. 2001. Differentiation in reproductive strategy between sexual and asexual populations of Antennaria parlinii (Asteraceae). - Evol. Ecol. Res. 3: 311-330.

Olivieri, I. and Berger, A. 1985. Seed dimorphism and dispersal: physiological, genetic and demographical aspects. - In: Jacquard, P. 
et al. (eds), Genetic differentiation and dispersal in plants. Springer, pp. 413-429.

Olivieri, I. et al. 1983. Reproductive systems and colonizing strategy of two species of Carduus (Compositae). - Oecologia 60: $114-117$.

Peroni, P. A. 1994. Seed size and dispersal potential of Acer rubrum (Aceraceae) samaras produced by populations in early and late successional environments. - Am. J. Bot. 81: 1428-1434.

Phillips, B. L. et al. 2006. Invasion and the evolution of speed in toads. - Nature 439: 803-803.

Phillips, B. L. et al. 2008. Reid's paradox revisited: the evolution of dispersal kernels during range expansion. - Am. Nat. 172: S34-S48.

Píco, F. X. et al. 2003. Fitness traits and dispersal ability in the herb Tragopogon pratensis (Asteraceae): decoupling the role of inbreeding depression and maternal effects. - Plant Biol. 5: 522-530.

Pignatti, S. 1982. Flora d'Italia. - Edagricole.

Pitelka, L. F. 1997. Plant migration and climate change. - Am. Sci. 85: 464-473.

Platt, W. J. and Weiss, J. M. 1977. Resource partitioning and competition within a guild of fugitive prairie plants. - Am. Nat. 111: 479-513.

Prince, R. D. and Benoit, D. L. 1995. Interpopulation variation of pappus length and follicle characteristics of common milkweed. - Can. J. Plant Sci. 75: 727-730.

Riba, M. et al. 2005. Variation in dispersal traits in a narrowendemic plant species, Centaurea corymbosa Pourret. (Asteraceae). - Evol. Ecol. 19: 241-254.

Roach, D. A. and Wulff, R. D. 1987. Maternal effects in plants. - Annu. Rev. Ecol. Evol. Syst. 18: 209-235.
Ronce, O. et al. 2005. Plastic changes in dispersal along ecological succession: theoretical predictions from an evolutionary model. - J. Ecol. 93: 431-440.

Sheldon, J. C. and Burrows, F. M. 1973. The dispersal effectiveness of the achene-pappus units of selected Compositae in steady winds with convection. - New Phytol. 72: 665-675.

Soons, M. B. and Heil, G. W. 2002. Reduced colonization capacity in fragmented populations of wind-dispersed grassland forbs. - J. Ecol. 90: 1033-1043.

Stephens, P. A. et al. 1999. What is the Allee effect? - Oikos 87: $185-190$.

Taylor, C. M. and Hastings, A. 2005. Allee effects in biological invasions. - Ecol. Lett. 8: 895-908.

Travis, J. M. J. and Dytham, C. 2002. Dispersal evolution during invasions. - Evol. Ecol. Res. 4: 1119-1129.

Van Kleunen, M. and Johnson, S. D. 2005. Testing for ecological and genetic Allee effect in the invasive shrub Senna didymobotrya (Fabaceae). - Am. J. Bot. 92: 1124-1130.

Venable, D. L. and Burquez, A. 1990. Quantitative genetics of size, shape, life-history, and fruit characteristics of the seed heteromorphic composite Heterosperma pinnatum. II. Correlation structure. - Evolution 44: 1748-1763.

Verloove, F. 2006. Catalogue of neophytes in Belgium. - Natl Bot. Gard. Belgium.

Vitousek, P. M. et al. 1997. Introduced species: a significant component of human-caused global change. - N. Z. J. Ecol. 21: $1-16$.

Welham, C. V. J. and Setter, R. A. 1998. Comparison of sizedependent reproductive effort in two dandelion (Taraxacum officinale) populations. - Can. J. Bot. 76: 166-173. 